\title{
Simulation Research on Control Strategy for Push-pull Forward DC-DC Converter
}

\author{
Zhen-Qiang Li, Xu-Liang Zhang, Xiang Wen \\ College of Electrical and Information Engineering, Guangxi University of Science and Technology, Liuzhou Guangxi, China \\ E-mail: Lizhenqiang67@163.com,491599487@qq.com,920592971@qq.com
}

\begin{abstract}
For the Push-pull Forward (PPF) DC-DC converter, in order to find an ideal control strategy, the mathematical model of the PPF DC-DC converter can be obtained by the small-signal analysis method. According to the mathematical model, we give three control strategies to design PID controller, Fuzzy controller and Fuzzy PID controller. The simulation results show that the Fuzzy PID controller has the advantages of small overshoot, short adjustment time and small steady state error, so it has better control effect.
\end{abstract}

Keywords- push-pull; converter; fuzzy controller; control strategy

\section{INTRODUCTION}

PPF DC-DC converter ${ }^{[1,2]}$ is the most common type of high power converter topology ${ }^{[3]}$ circuit, The topology of the converter has the following three advantages:(1)The transformer $^{[1]}$ between input and output ,has realized the electrical isolation ${ }^{[2]}$, thereby reducing the mutual interference between high side and low voltage side;(2)The output current transient response speed is very high, the voltage output characteristic is very good;(3)The push-pull $^{[4,5]}$ converter transformer belongs to double polar magnetization, there is no air gap in transformer and the leakage inductance and resistance of copper loss are much smaller than the single polarity magnetic pole transformer, so the push-pull converter has the highest voltage utilization, in the case of the input voltage is very low, it can still maintain a big output power. Therefore, study the push-pull converter is of great significance.

To achieve stabilized output, through the converter output voltage sampling, we can realize the closed loop feedback control ${ }^{[6]}$.Based on voltage type push-pull converter; this paper designed three kinds of control strategies to simulation research.

The conventional PID [6, 7] controller has its characteristics such as simple structure, convenient use and good stability characteristics, commonly used in linear system is very wide. Fuzzy ${ }^{[6,7]}$ controller can solve the problem of control which the system is difficult to modeling, because it does not need precise model of controlled object, the response time is short. But fuzzy controller do not have integral element, so it is difficult to eliminate the steady-state error. Fuzzy PID controller combine fuzzy controller and PID controller, the fuzzy PID controller makes full use of the advantages of both, so that it can achieve good control effect.

\section{PUSH-PULL FORWARD DC-DC CONVERTER}

\section{A. Push-Pull Dc-Dc Converter Topology}

The structure of the push-pull forward converter is shown in fig.1.

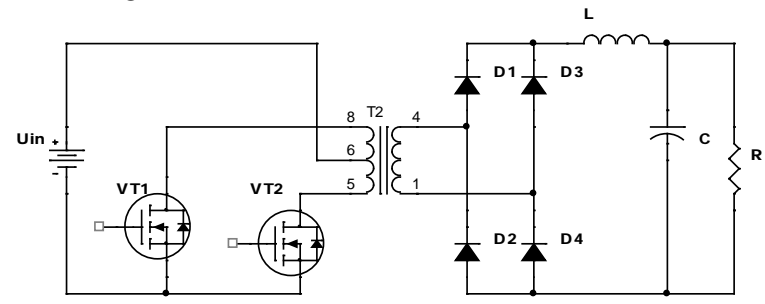

Figure 1. PPF converter topology.

$U_{i n}$ is The input voltage, $V T_{1}$ and $V T_{2}$ are the two power switches, the switching frequency is f. $D_{1} \sim D_{4}$ are rectifier diode, Respectively, $\mathrm{L}$ and $\mathrm{C}$ are filtering inductance and filter capacitor. Transformer turn ratio is $\mathrm{n}$.

In one work cycle, $V T_{1}$ and $V T_{2}$ open and shut off in turn, when $V T_{1}$ or $V T_{2}$ work, converter Transmission power.

\section{B. PPF Converter Small Signal Model}

In order to design the controller, firstly we need to establish the small signal model of PPF converter, and then derive the transfer function of the main circuit, assuming main circuit meets the following conditions:

- All parasitic components are neglected except the transformer leakage inductance;

- Transformer winding is completely symmetrical;

- $\quad$ The magnetizing current is zero;

When $V_{1}$ or $V_{2}$ work, meet the following formula:

$$
\left\{\begin{array}{l}
i_{i n}=n i_{L f} \\
u_{F}=n u_{i n}
\end{array}\right.
$$

When $V_{1}$ and $V_{2}$ shutoff at the same time, meet the following formula:

$$
\left\{\begin{array}{c}
i_{\text {in }}=\frac{1}{2} n i_{L f} \\
u_{F}=0
\end{array}\right.
$$

Among them, transformer turn ratio is defined as 
$n=N_{2} / N_{1}$, separately, $i_{i n}, i_{L f}, U_{F}, u_{\text {in }}$ represent the input current, inductor current, rectifier pulse voltage, The input voltage transient variable.

Assuming that $(X)_{T S}$ is averages of each variable in a switch cycle, and then the input and output satisfy the following relationship between average models:

$$
\left\{\begin{array}{c}
\left(i_{i n}\right)_{T s}=\frac{1}{2} n(1+d)\left(i_{L f}\right)_{T s} \\
\left(u_{F}\right)_{T s}=n d\left(u_{i n}\right)_{T s}
\end{array}\right.
$$

The voltage, current and duty cycle decompose into DC, AC component, and then meet the following formula:

$$
\begin{aligned}
& \left(u_{i n}\right)_{T s}=U_{i n}+\hat{u_{i n}}(t) ;\left(i_{i n}\right)_{T s}=I_{i n}+\hat{i_{i n}}(t) ; \\
& \left(u_{F}\right)_{T s}=U_{F}+\hat{u_{F}}(t) ;\left(i_{L f}\right)_{T s}=I_{L f}+\hat{i_{L f}}(t) ; \\
& d=D+\hat{d}(t)
\end{aligned}
$$

Ignore the higher order infinitesimal component; the following fractions can be obtained:

$$
\left\{\begin{array}{c}
I_{\text {in }}+\hat{i}_{\text {in }}(t)=\frac{1}{2} n(1+D)\left(I_{L f}+\hat{i}_{L f}(t)\right)+\frac{1}{2} n I_{L f} \hat{d} \\
U_{F}+\hat{u}_{F}(t)=n D\left(U_{\text {in }}+\hat{u}_{\text {in }}(t)\right)+n U_{\text {in }} \hat{d}
\end{array}\right.
$$

By the above fraction, we can get PPF small signal circuit model:

$$
\left\{\begin{array}{c}
\hat{i}_{\text {in }}(t)=\frac{1}{2} n(1-D) i_{L f}(t)+\frac{1}{2} n I_{L f} \hat{d}+n D \hat{i}_{L f}(t) \\
\hat{u}_{F}(t)=n D \hat{u}_{\text {in }}(t)+n U_{\text {in }} \hat{d}
\end{array}\right.
$$

According to the above equation, establish small signal model which is shown in figure 2,among them, $\hat{i}_{0}(t)$ is the current variation of load change; $R_{L}$ is inductance parasitic resistance; $R_{C}$ is the output filter capacitor parasitic resistance; $\mathrm{R}$ is load resistance.

Deduced between different signal transfer function, that is as follows:

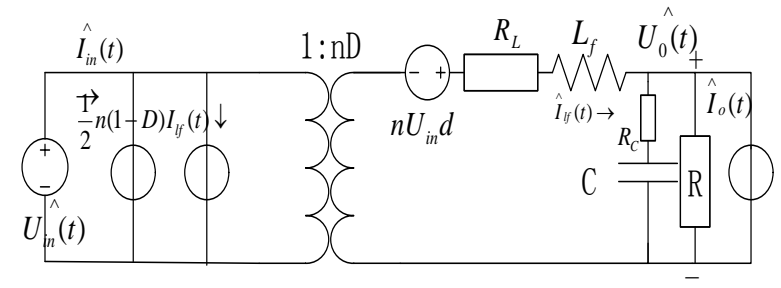

Figure 2. PPF converter small signal model.

(1): The transfer functions between duty ratio $\hat{d}_{s}$ and inductor current $i_{L}(s)$ :

$$
\begin{gathered}
G_{d i}(s)=\left.\frac{\hat{i}_{L f}(s)}{\hat{d}(s)}\right|_{\hat{u}_{\text {in }(s)=0, i_{o}(\hat{s})=0}}=\frac{n U_{i n}}{R+R_{L}} \bullet \\
s C_{f}\left(R+R_{C}\right)+1 \\
s^{2} \frac{L_{f} C_{f}\left(R+R_{C}\right)}{R+R_{L}}+s\left(\frac{L_{f}+R_{L} C_{f} R}{R+R_{L}}+R_{C} C_{f}\right)+1
\end{gathered}
$$

(2): The transfer functions between inductor current $i_{L}(s)$ and the output voltage $\hat{U}_{o}(s)$ :

$$
G_{i u}(s)=\left.\frac{\hat{U_{0}}(s)}{\hat{i_{L f}}(s)}\right|_{\hat{\hat{u}_{\text {in }(s)=0, i_{o}(\hat{s})=0}}}=R \frac{s R_{C} C_{f}+1}{s C_{f}\left(R+R_{C}\right)+1}
$$

(3): The transfer functions between input voltage $\hat{U}_{\text {in }}(s)$ and the output voltage $\hat{U}_{o}(s)$ :

$$
\begin{array}{r}
A(s)=\left.\frac{\hat{u_{0}}}{\hat{u_{i n}}(s)}\right|_{\hat{i_{0}(s)=0, \hat{d}=0}}=\frac{n D R}{R+R_{L}} \bullet \\
s R_{C} C_{f}+1 \\
s^{2} \frac{L_{f} C_{f}\left(R+R_{C}\right)}{R+R_{L}}+s\left(\frac{L_{f}+R_{L} C_{f} R}{R+R_{L}}+R_{C}\right)+1
\end{array}
$$

(4): The transfer function between duty ratio $\hat{d}_{s}$ and the output voltage $\hat{U}_{o}(s)$ :

$$
\begin{aligned}
& G_{v d}(s)=\left.\frac{\hat{u}_{0}(s)}{\hat{d}(s)}\right|_{\hat{u}_{i n}(s)=0, \hat{i}_{0}(s)=0}= \\
& \frac{2 n U_{i n} R}{R+R_{L}} \frac{R_{C} C_{f} s+1}{s^{2} \frac{L C_{f}\left(R+R_{C}\right)}{R+R_{L}}+s\left(\frac{L+R_{L} R C_{f}}{R+R_{L}}+R_{C} C_{f}\right)+1}
\end{aligned}
$$




$$
\approx 2 n U_{\text {in }} \frac{R_{C} C_{f} s+1}{s^{2} L C_{f}+s\left[L+\left(R_{C}+R_{L}\right) C\right]+1}
$$

\section{CONTROL STRATEGY DESIGN}

As known the transfer function between duty ratio and the output voltage, on this basis, respectively, design PID controller, fuzzy controller and fuzzy PID controller, structure as shown in figure 3.

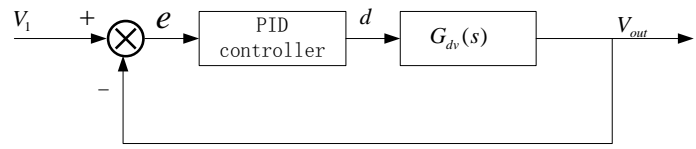

(a)PID controller

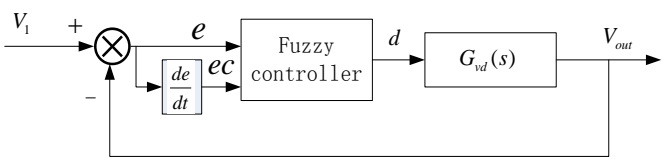

(b) Fuzzy controller

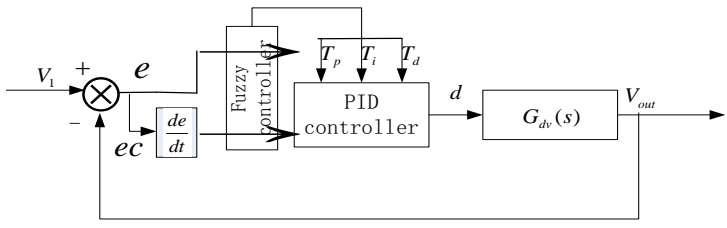

(c) Fuzzy PID controller

Figure 3. Three kinds of controller.

Respectively, take the main circuit parameters:

$U_{\text {in }}=20 \mathrm{~V}, L_{f}=500 \mu \mathrm{H}, C_{f}=1880 \mu \mathrm{F}, R=52 \Omega$, $f=50 \mathrm{kHz}, R_{L}=0.1 \Omega, R_{C}=0.04 \Omega, n=4$.

\section{A. PID Controller Design}

The structure diagram composed of PID controller system is shown in figure 3(a). The parameter is substituted into $G_{d v}(s)$,

$$
G_{d v}(s)=\frac{1.235 \times 10^{-2} s+160}{0.94 \times 10^{-6} s^{2}+0.27 \times 10^{-3} s+1}
$$

Set the transfer function of PI as $T(s)=1+1 / s$, then the open loop transfer function turn into:

$$
G(s)=G_{d v}(s) \cdot T(s)=\frac{1.235 \times 10^{-2} s^{2}+160 s+160}{s^{3} \times 0.94 \times 10^{-6}+0.27 \times 10^{-3} s^{2}+s}
$$

\section{B. Fuzzy Controller Design}

The structure diagram of fuzzy controller is shown in figure 4(b).

The process of deaigning Fuzzy PID controller as follow:

(1) To determine the input variables as error and the error rate, the output variable define as u:

$e(k)=V_{\text {ref }}-V_{o}(k), e c(k)=e(k)-e(k-1)$

(2) Select the fuzzy subset, $u=\{\mathrm{NB}, \mathrm{NM}, \mathrm{NS}, \mathrm{ZE}, \mathrm{PS}$,
$\mathrm{PM}, \mathrm{PB}\}$.

(3) Determine the fuzzy control rules.

(4) By solving the fuzzy, output control quantity, and then after processing, output duty ratio.

\section{Fuzzy PID Controller Design}

The structure diagram of fuzzy PID controller is shown in figure 3(c).

Fuzzy PID controller combine fuzzy controller and PID controller, take error and the error rate as input, using the fuzzy control rules, modify the PID parameters online, it can satisfy the requirement of PID parameters at anytime.

The design process similar to the fuzzy controller, the input variables are still error and the error rate, while, the output variables turn into proportional, integral and differential parameters, mean kp, ki and kd.

When the system run, by processing the results of the fuzzy logic rules, look-up table and operate, complete the adjustment of PID parameters online.

\section{THE RESULTS OF SIMULATION AND ANALYSIS}

In order to verify the effect of above three kinds of control strategies, using the MATLAB/Simulink software built simulation model of the three schemes, the initial PID parameters set the same. Set the output voltage as $V_{\text {out }}=150 \mathrm{~V}$, the simulation model as shown in figure 4, the simulation results as shown in figure 5 .

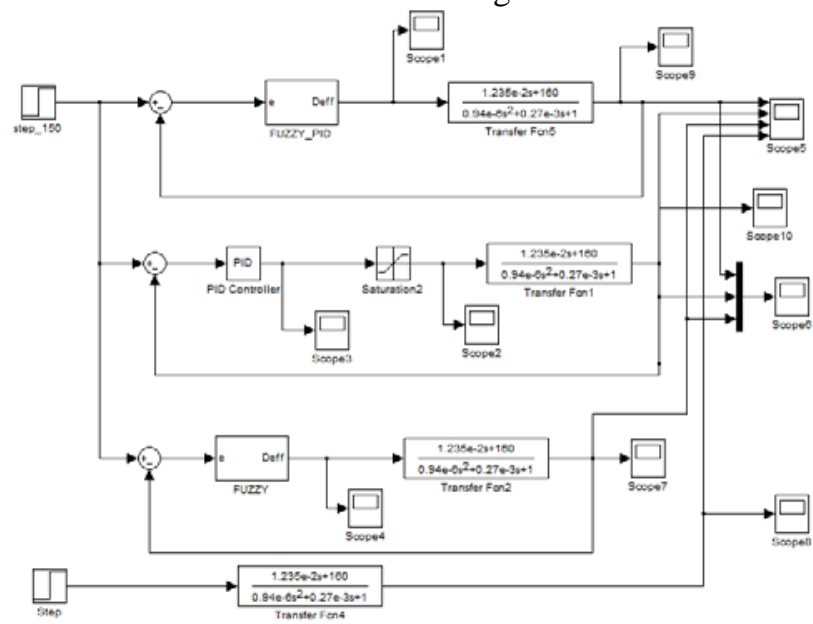

Figure 4. Simulink simulation model.

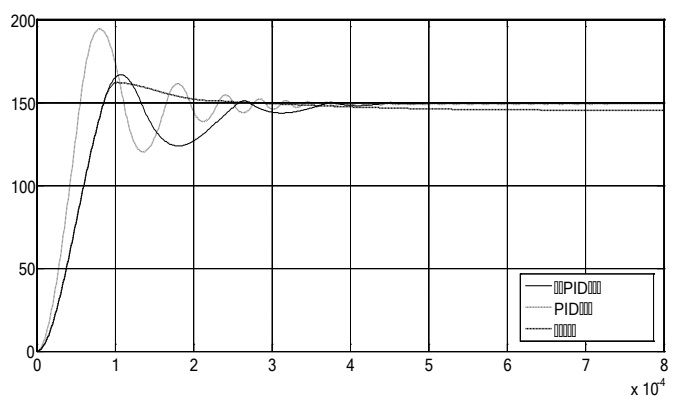

Figure 5. The simulation results of the three kinds of control scheme 
The simulation shows PID controller has big overshoot and debug time is long; Fuzzy PID controller has small overshoot, the debug time is shorter than PID controller, steady-state error is almost zero; Fuzzy controller has the minimum amount of overshoot, and the shortest debug time, but steady-state error is larger. Details are shown in table 1.

TABLE I. TABLE THE SIMULATION RESULTS OF THE THREE KINDS OF CONTROL SCHEME

\begin{tabular}{|c|c|c|c|}
\hline simulated effect & $\begin{array}{c}\text { PID } \\
\text { controller }\end{array}$ & $\begin{array}{c}\text { Fuzzy } \\
\text { controller }\end{array}$ & $\begin{array}{c}\text { Fuzzy PID } \\
\text { controller }\end{array}$ \\
\hline overshoot & big & small & small \\
\hline debug time & long & short & middle \\
\hline steady-state error & middle & big & small \\
\hline
\end{tabular}

\section{SUMMARY}

This article design three kinds of control strategy and do the simulation experiment for buck type PPF converter. The experimental results show that fuzzy PID controller has smaller overshoot and steady-state error, the simulation effect is better.

\section{ACKNOWLEDGEMENT}

This research was financially supported by the Guangxi province natural Science Foundation (2013GXNSFCA019020). Thanks are due to professor Li for assistance with the experiments and to W. Xiang for valuable discussion.

\section{REFERENCES}

[1] LIU Weu-han, WANG qi. Small Signal Modeling of Double-Loop Controlled Push-pull Forward DC-DC Converter [J]. The World of
Power Supply, 2008(1): 58-60.

[2] Papathomas, Thomas V.On the Stability of Peak Current-Controlled Converters: Analysis, Simulation, and Experiments. Industrial Electronics, IEEE Transactions on.

[3] Zhou Xingsheng, Chen Dan, Jamerson C. Leadingedge modulation voltage-mode control with flux unbalances correction for push-pull converer. In: IEEE APEC.

[4] Luo Ping, Li Zhaoji, Xiong Fugui, et al. Fuzzy pulse skip modulation mode in DC/DC converter. 2004IEEE International Power Electronics Congress.

[5] Benjamin J Patella, Aleksandar Prodic. High-Frequency digital PWM controller IC for DC-DC converter. IEEE Transactions on Power Electronics.

[6] T. Qi, C. Li, W. Kai, L. Yan."Research on Motion Control of Mobile Robot with Fuzzy PID Arithmetic," The Ninth International Conference on Electronic Measurement \& Instruments (ICEMI" 2009).

[7] Guo, Liping, Hung, John Y., Nelms, R. M. Evaluation of DSP-based PID and fuzzy controllers for DC-DC converters. IEEE Transactions on Industrial Electronics. 